\title{
Zum 80. Geburtstag von Dieter Spethmann
}

Am 27. März 2006 vollendete Prof. Dr. jur. Dr. Ing.-E.h. Dieter Spethmann sein 80. Lebensjahr, das er - wie alle Jahre zuvor - in produktivem „Unruhestand“ verbrachte. Nach seinem Ausscheiden bei der Thyssen AG, die er von 1973 bis 1991 als Vorstandsvorsitzender leitete, wählte er nämlich nicht das beschauliche Leben eines Pensionärs, sondern er ist bis zum heutigen Tage in nationalen und internationalen Aufsichtsgremien sowie als Rechtsanwalt, Berater und streitbarer Publizist vor allem zur europäischen Wirtschafts- und Währungspolitik tätig.

Dieter Spethmann wurde am 27. März 1926 in Essen geboren und studierte Volkswirtschaftslehre und Rechtswissenschaften an den Universitäten Kiel, Bonn und Köln. Nach seinem Studium, das er 1948 mit dem Referendarexamen und 1952 mit der Grossen Juristischen Staatsprüfung abschloss, war er zunächst Assistent für Auslandsfinanzen und Sonderaufgaben der Gelsenkirchener Bergwerks AG und von deren Muttergesellschaft Vereinigte Stahlwerke. 1954 erfolgte die Promotion zum Dr. jur., 1955 trat er als Assistent des Vorstandsvorsitzenden in die August Thyssen-Hütte ein. Er blieb dem Unternehmen bis zu seinem 65. Lebensjahr verbunden, zunächst als Leiter der Abteilung Finanzen und Beteiligungen, dann als Mitglied des Vorstands der Tochtergesellschaft Handelsunion AG, als Vorsitzender des Vorstands der Tochtergesellschaft Deutsche Edelstahlwerke und schließlich als Mitglied des Vorstands und Vorsitzender des Vorstands der August Thyssen-Hütte AG und der späteren Thyssen AG.

Bis zum heutigen Tage verbunden ist er der List Gesellschaft e.V. Bereits 1962 wurde er Mitglied im erweiterten Vorstand, im Dezember 1968 dann stellvertretender Vorsitzender und 1972 schließlich Vorsitzender der Gesellschaft. Zunächst mit Dr. Albrecht Düren, dann gemeinsam mit Prof. Dr. Hans Besters bestimmte er bis 1996 die Geschicke der List Gesellschaft, die wesentlich von seinem Sachverstand und seinem großen persönlichen Engagement profitierte. Auch nach Niederlegung des Vorsitzes blieb er der Gesellschaft treu und steht ihr als Mitglied des Vorstands noch immer mit Rat und Tat zur Seite.

Vorstand und Mitglieder der Gesellschaft danken ihm für sein langjähriges großes Engagement. 